\title{
The paradox of compensated silicon
}

\author{
Andres Cuevas \\ Department of Engineering, The Australian National University, Canberra ACT 0200, Australia
}

\begin{abstract}
Compensated doping is typical of upgraded metallurgical silicon. The relatively low carrier mobility associated to high concentrations of both acceptors and donors leads to paradoxical effects on solar cell performance. While the short-circuit current is expected to decrease compared to noncompensated silicon of the same resistivity, the open-circuit voltage is predicted to increase when bulk recombination is the dominant loss mechanism. On the other hand, surface recombination is predicted to have a greater impact on compensated $\mathrm{Si}$ wafers and to result in a lower effective carrier lifetime. These effects are important to understand measurements of compensated Si wafers and devices.
\end{abstract}

\section{Keywords-compensated silicon, silicon solar cells}

\section{INTRODUCTION}

Lower grade silicon materials produced via upgraded metallurgical methods (UMG-Si) offer significant advantages over the well established Siemens process. Drastic reductions in the energy consumption and carbon footprint of solar cells, together with simpler equipment and processes can lead to a shorter energy payback time for the PV modules and a capability for ramping up silicon production capacity to meet a rapidly growing demand. UMG-Si does have, nevertheless, significant short-comings, the most obvious being that the material is relatively "dirty", laden with impurities such as metals, carbon and oxygen. Although exacerbated, this high contamination is not unlike the multicrystalline silicon commonly used today, where the learning of the last few years has revealed that many of those impurities can be gettered out or rendered almost inactive by preferential precipitation at grain boundaries and crystal defects. These techniques can also be applied to UMG-Si and are partly behind the achievement of conversion efficiencies up to $16 \%$ for industrial size [1] and $18 \%$ for laboratory size solar cells made with $100 \%$ UMG-Si [2].

A distinctive characteristic of UMG-Si is that it usually contains a large amount of both boron and phosphorus (in general, of both p-type and n-type dopants), as a consequence of the difficult elimination of these elements using metallurgical processes. This results in silicon ingots that have compensated doping. In fact, a delicate balance between acceptor and donor atoms is one of the tools to obtain material with a resistiviy acceptable for solar cells $(0.1-10 \Omega \mathrm{cm})$. But resistivity control using compensation is difficult, due to the different solid to liquid segregation coefficients of $\mathrm{P}$ and $\mathrm{B}$, which produce a strongly varying resistivity along the mc-Si ingot. Frequently the material becomes over-compensated towards the top of the ingot, that is, changes from $p$-type to $n$ - type, and is unusable for current industrial cell technology. It may well be that in the future n-type Si will find acceptance and even predilection, but for the time being the reduction of boron and phosphorus in the raw material is widely regarded as one of the key issues for UMG-Si. Typical values achieved by current UMG-Si technology are 0.53-0.89 ppmw for B and 1.15.2 ppmw for $\mathrm{P}[3,4]$.

Highly compensated silicon is still poorly understood and this poses interesting scientific challenges. Two are the main properties of interest for solar cells: carrier lifetime and carrier mobility. Both can be expected to be lower in compensated silicon, compared to their values in non-compensated material. Our preliminary experiments on single crystal compensated silicon have shown that carrier lifetimes are lower, by approximately a factor of two, than those in non compensated control material [5]. Dopant compensation can also be expected to have a negative effect on the mobility of electrons and holes. Most empirical models used to calculate the mobility as a function of doping predict that the increased number of scattering centres present in compensated silicon (that is, the ionised boron and phosphorus atoms) will produce a reduction of the mobility. In this paper we investigate possible implications of compensation doping on the performance of silicon solar cells using a simple, but comprehensive modelling tool, QSS-Model [6]. The emphasis is on the impact of carrier mobility.

\section{UNDERSTANDING THE RESISTIVITY OF COMPENSATED SILICON}

The importance of having an accurate knowledge of the mobility of electrons and holes in silicon as a function of dopant density cannot be overemphasised. Reliable data exists for monocrystalline silicon doped with either boron or phosphorus, but not both. When both dopants are present, as in compensated material, those mobility models may still be applied, keeping in mind that they have not been validated experimentally yet. Here we will use an empirical expression based on Thurber et al [7] and Arora et al [8] and used in modelling programs such as PC1D [9]. This expression assumes that both $\mu_{\mathrm{n}}$ and $\mu_{\mathrm{p}}$ have a functional dependence on the sum of acceptor and donor densities $\mathrm{N}_{\mathrm{A}}+\mathrm{N}_{\mathrm{D}}$. A more recent empirical mobility model proposed by Reggiani et al. [10] gives essentially the same results.

Once a hot probe polarity test is performed to determine its conductivity type, $\mathrm{n}$ or $\mathrm{p}$, the simplest characterisation of a silicon material is to measure its resistivity. This permits to evaluate the equilibrium majority carrier density, which 
approximately equals the net dopant density, $\mathrm{N}_{\mathrm{A}}-\mathrm{N}_{\mathrm{D}}$. In the case of compensated silicon, however, the same net dopant density can result from many combinations of acceptor and donor concentrations, as can be observed in Fig. 1. Note that the contour plots in the n-type and p-type sectors are not perfectly symmetrical, due to the different mobilities for electrons and holes in silicon. Hence a single resistivity measurement is not enough to determine the acceptor and donor densities separately. To do that, it is possible to use a new technique proposed by Macdonald et al. [11] in which the acceptor concentration is found from the time rate of the reaction between those acceptors and residual iron present in the material.

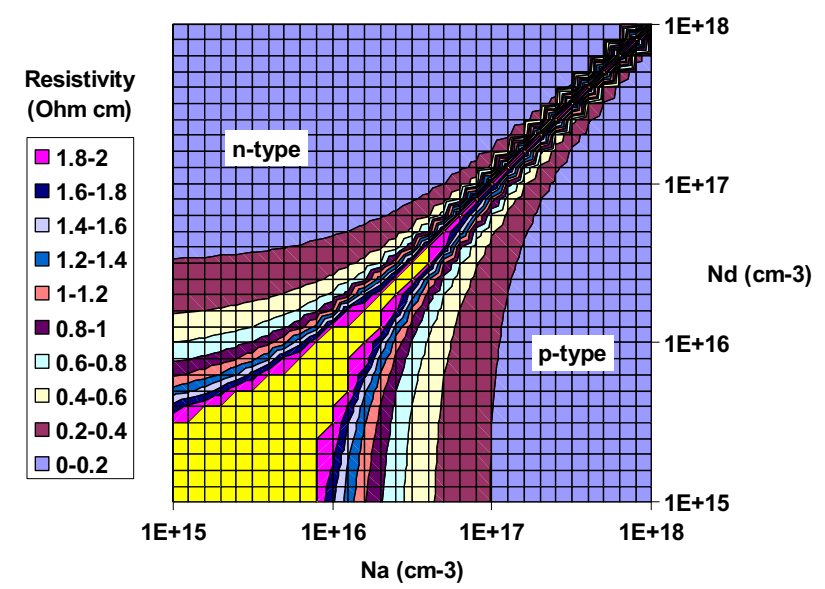

Figure 1. Resistivity of silicon as a function of both acceptor and donor concentrations. Curves are only plotted for the resistivity range below $2 \Omega \mathrm{cm}$. Mobility model of Thurber et al. at 300K [7,8].

A common approach to determine the concentrations of boron (actually, net acceptors) and phosphorus (net donors) is to measure the resistivity in several positions along the ingot and fit it with a model for dopant segregation [12, 13]. The concentration of dopant atoms as a function of position is given by the following equation, proposed by Scheill [14]:

$$
C=k_{e f f} C_{0}(1-x)^{\left(k_{e f f}-1\right)}
$$

where $C_{0}$ is the concentration of the element in the melt and $k_{\text {eff }}$ is the effective segregation coefficient. An example is shown in Fig. 2, where the resistivity curve is a fit to measurements performed at Ferroatlantica $\mathrm{I}+\mathrm{D}$ in an experimental UMG-Si ingot [15]. The markedly different segregation coefficients of boron, 0.8 [16], and phosphorus, 0.35 , lead in this case to a conversion from p-type to n-type and to a spike in resistivity at approximately $90 \%$ from the bottom of the ingot. Lilbal et al. [17] have observed a similar resistivity spike and type change, while Einhaus et al. [4] did not find such a sharp spike in resistivity, although the trend is qualitatively similar.

The combined impurity segregation and resistivity modelling permits to estimate the concentration of boron and phosphorus in the feedstock material used to grow the ingot. The results for the example shown in Fig. 2 are $1.4 \mathrm{ppmw}$ (3.64ppma) boron and 3.2ppmw (2.9ppma) phosphorus. It should be emphasised that this approach relies on an accurate knowledge of the mobilities of electrons and holes in compensated silicon and also of the segregation coefficients. In the above we have assumed that both $\mu_{n}$ and $\mu_{p}$ have a functional dependence on $\mathrm{N}_{\mathrm{A}}+\mathrm{N}_{\mathrm{D}}$. If we assumed instead that $\mu_{n}$ depends only on $N_{D}$ and $\mu_{p}$ on $N_{A}$, the result of fitting the resistivity curve in Fig. 2 would be $1.2 \mathrm{ppmw}$ boron and 2.9 ppmw phosphorus, that is, approximately $20 \%$ lower.

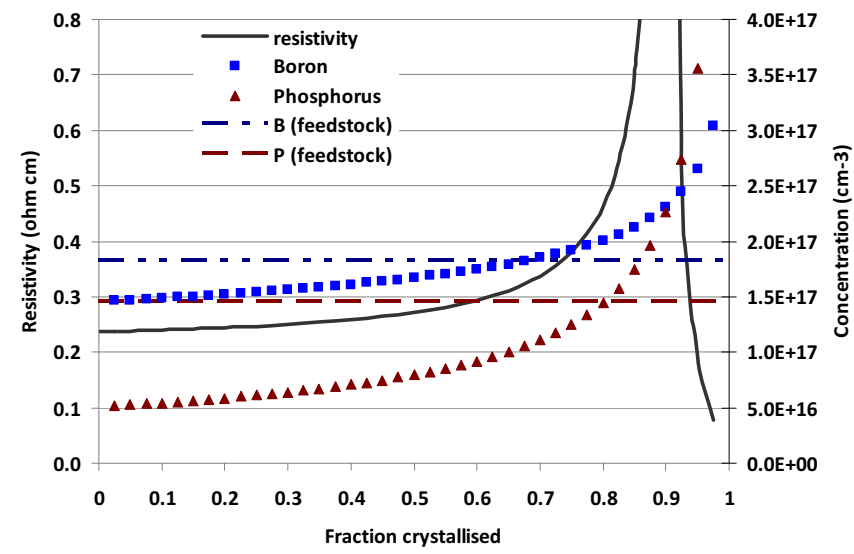

Figure 2. Atomic boron and phosphorus concentrations in a highly compensated silicon ingot, and modelled resistivity.

Another source of uncertainty comes from the possibility that the mobility of multicrystalline silicon (mc-Si) may be significantly lower than that of single crystalline silicon. For example, if the mobility was $70 \%$ of the normal values for crystalline $\mathrm{Si}$, the estimated $\mathrm{B}$ and $\mathrm{P}$ concentrations would be $43 \%$ higher than those given above. Hall-effect measurements [16] have shown that the majority carrier (hole) mobility in $\mathrm{p}$ type mc-Si is approximately $60 \%$ of typical values found in mono-Si for material with a similar resistivity. This was attributed to grain boundaries and defects in mc-Si. Another recent paper by Einhaus et al. [4] also reports a reduced mobility in mc-Si, approximately $75 \%$ of its single crystal value. It should be noted that these measurements correspond to the majority carrier mobility and, whereas they are of great importance to establish a correlation between measured resistivity and equilibrium carrier density, they do not bear full significance to determine the minority carrier diffusion length. The vertical grain structure of mc-Si leads to the expectation that the minority carrier density should be approximately the same as in mono-Si, since carriers diffuse vertically towards the junction in the common Si solar cell structure.

Mobility measurements in compensated Si are scarce. An early paper by Pizzini [18] indicated that compensation did not have a large effect on majority carrier mobility in mono-Si. More recent work [16] using compensated multicrystalline silicon has reached the same conclusion, at least for the relatively low compensation levels studied (resistivities in the range $1-4 \mathrm{ohmcm}$ ). In contrast, the measurements of Einhaus et al [4] on strongly compensated $m c-S i$ produced by UMG methods show a strong reduction in hole mobility compared to non-compensated mc-Si of the same resitivity. Clearly, it is of the utmost importance to measure the mobility of mc-Si and of 
compensated mc-Si. In this paper we will maintain the traditional assumption that the mobility in $\mathrm{mc}-\mathrm{Si}$ is not significantly different from that in monocrystalline $\mathrm{Si}$.

\section{FIRST CASE STUDY: COMPENSATED SILICON SOLAR CELL DOMINATED BY BULK RECOMBINATION}

Silicon wafers are commonly selected by solar cell manufacturers based on their resistivity. Today the norm is to use p-type wafers with a resistivity in the proximity of $1 \Omega \mathrm{cm}$, but UMG-Si usually has a lower resistivity, due to a higher concentration of dopants. Therefore, we shall compare compensated vs. non-compensated material that have the same resistivity, but different acceptor and donor densities.

A case representative of UMG-Si is a wafer taken from the ingot in Fig. 2 at position $77 \%$, with a resistivity of $0.41 \Omega \mathrm{cm}$. The modeling of $\mathrm{B}$ and $\mathrm{P}$ segregation permits to determine an expected concentration of $2 \times 10^{17} \mathrm{~cm}^{-3}$ boron and $1.3 \times 10^{17} \mathrm{~cm}^{-3}$ phosphorus atoms. Table I summarizes the properties of this compensated material compared to non compensated p-type silicon, which would reach the same resistivity with just $4 \times 10^{16} \mathrm{~cm}^{-3}$ boron atoms. The mobility model predicts that there is a strong reduction in carrier mobility in the compensated material, for both electrons and holes. We assume a wafer thickness of $200 \mu \mathrm{m}$ and a significant contamination level, defined by interstitial iron and chromium concentrations of $1 \times 10^{12} \mathrm{~cm}^{-3}$ each. A two-center SRH recombination model using literature data for $\mathrm{Fe}$ and $\mathrm{Cr}$ recombination centers results in a bulk minority carrier lifetime of about $\tau_{b u l k} \sim 2 \mu \mathrm{s}$, practically unchanged by compensation. As for surface recombination, we model it with a saturation current density of $J_{o e}=1 \times 10^{-13} \mathrm{Acm}^{-2}$ at both sides of the wafer. This is representative of a good phosphorus emitter at the front, and also of a rear surface that may be passivated with a dielectric and contacted with metal in $5-10 \%$ of its surface.

The solar cell modeling results, shown in Table II, indicate that compensation will result in a lower short-circuit current. Since the bulk lifetime is very similar, this is due to a lower mobility, which produces a lower minority carrier diffusion length, $L_{n}=48 \mu \mathrm{m}$ vs. $L_{n}=71 \mu \mathrm{m}$. The results for the open-circuit voltage are surprising: according to our modeling, compensated material would produce a $15 \mathrm{mV}$ higher $\mathrm{V}_{\mathrm{oc}}$ than noncompensated silicon. The net result of the opposing trends in $\mathrm{J}_{\mathrm{sc}}$ and $\mathrm{V}_{\mathrm{oc}}$ is a very similar efficiency in both cases.

To understand the reasons behind a higher voltage, Table II also shows the excess carrier concentration at the front side of the wafer, where the pn junction is located. The terminal voltage of a conventional $n^{+} p$ silicon solar cell is given by:

$$
V=\frac{k T}{q} \ln \left(\frac{\Delta n_{\text {front }} p_{o}}{n_{i}^{2}}\right)
$$

What happens is that both the excess minority carrier concentration and the majority (hole) concentrations are significantly higher in the compensated material, and this leads to a higher voltage. The main contribution to the increased voltage comes from a higher majority carrier density
( $p \approx p_{0} \approx N_{A}-N_{D}$ ) needed in the compensated material to achieve a given resistivity despite a lower mobility. On the other hand, the higher excess minority carrier density is a result of the lower minority (electron) carrier mobility assumed in our model (in line with the reduction in majority carrier mobility). This leads to a lower minority carrier diffusion length and to a "packing" of carriers towards the front side of the wafer.

The increase in $\mathrm{V}_{\mathrm{oc}}$ becomes less noticeable if surface recombination increases. For example, a $\mathrm{J}_{\mathrm{oe}}=1 \times 10^{-12} \mathrm{Acm}^{-2}$, which is typical of industrial $\mathrm{n}^{+}$solar cells, results in $\mathrm{V}_{\mathrm{oc}}=610$ $\mathrm{mV}$ for compensated and $\mathrm{V}_{\mathrm{oc}}=602 \mathrm{mV}$ for conventional materials. The effective carrier lifetime (note, not the bulk lifetime) that would be measured for such surface condition in the compensated wafer would be $0.83 \mu$ s. The importance of surface recombination is clarified in the next section.

TABLE I. PROPERTIES OF COMPENSATED AND NON-COMPENSATED SILICON OF THE SAME RESISTIVITY

\begin{tabular}{|l|l|l|l|l|l|l|}
\hline & $\begin{array}{l}\rho \\
(\Omega \mathrm{cm})\end{array}$ & $\begin{array}{l}\mathrm{N}_{\mathrm{A}} \\
\left(\mathrm{cm}^{-3}\right)\end{array}$ & $\begin{array}{l}\mathrm{N}_{\mathrm{D}} \\
\left(\mathrm{cm}^{-3}\right)\end{array}$ & $\begin{array}{l}p_{o} \\
\left(\mathrm{~cm}^{-3}\right)\end{array}$ & $\begin{array}{l}\mu_{p} \\
\left(\mathrm{~cm}^{2}\right. \\
/ \mathrm{Vs})\end{array}$ & $\begin{array}{l}\mu_{n} \\
\left(\mathrm{~cm}^{2}\right. \\
/ \mathrm{Vs})\end{array}$ \\
\hline Not comp. & 0.415 & $4.03 \times 10^{16}$ & 0 & $4 \times 10^{16}$ & 374 & 930 \\
\hline Compens. & 0.415 & $1.96 \times 10^{17}$ & $1.34 \times 10^{17}$ & $6.2 \times 10^{16}$ & 243 & 476 \\
\hline
\end{tabular}

TABLE II. SOLAR CELL MODELING FOR COMPENSATED AND NONCOMPENSATED SILICON OF $0.415 \Omega \mathrm{CM}$ RESISTIVITY.

\begin{tabular}{|l|l|l|l|l|l|l|}
\hline & $\begin{array}{l}\tau_{\text {bulk }} \\
(\mu \mathrm{s})\end{array}$ & $\begin{array}{l}L_{n} \\
(\mu \mathrm{m})\end{array}$ & $\begin{array}{l}\Delta n_{\text {front }} \\
\left(\mathrm{cm}^{-3}\right)\end{array}$ & $\begin{array}{l}J_{s c} \\
\left(\mathrm{~mA} / \mathrm{cm}^{2}\right)\end{array}$ & $\begin{array}{l}V_{o c} \\
(\mathrm{mV})\end{array}$ & $\begin{array}{l}\eta \\
(\%)\end{array}$ \\
\hline Not comp. & 2.1 & 71 & $5.3 \times 10^{13}$ & 29.85 & 616.5 & 15.2 \\
\hline Compensated & 1.9 & 48 & $6.3 \times 10^{13}$ & 28.5 & 632 & 14.9 \\
\hline
\end{tabular}

Silicon contains $1 \times 10^{12} \mathrm{~cm}^{-3}$ each interstitial iron and chromium (surface recombination, $J_{o e}=1 \times 10^{-13}$ $\mathrm{Acm}^{-2}$ ). Calculations performed at $300 \mathrm{~K}$. Excess minority carrier density, $\Delta n$ is calculated at the front side of the device, where the pn junction is located

\section{SECOND CASE STUDY: COMPENSATED SILICON WAFER DOMINATED BY SURFACE RECOMBINATION}

To better show the possible impact that a given surface recombination velocity can have on compensated material, we repeat the modeling exercise in the absence of any contamination, that is, using the intrinsic limits for bulk recombination in silicon imposed by the Auger and band to band processes. Surface recombination is modeled with the same saturation current density as in the previous section, $\mathrm{J}_{\mathrm{oe}}=1 \times 10^{-13} \mathrm{Acm}^{-2}$ at both sides of the wafer.

As can be seen in Table III, short-circuit currents, open circuit voltages and conversion efficiencies are practically the same in both cases. What is interesting to note in this example is that surface or emitter recombination has a greater impact on the effective lifetime of the compensated wafer $(22.6 \mu \mathrm{s})$ than on the non-compensated wafer $(34.8 \mu \mathrm{s})$. This is also illustrated by the different surface recombination velocity that a given $\mathrm{J}_{\mathrm{oe}}=1 \times 10^{-13} \mathrm{Acm}^{-2}$ produces in both wafers, $\mathrm{SRV}=414 \mathrm{~cm} / \mathrm{s}$ and $\mathrm{SRV}=270 \mathrm{~cm} / \mathrm{s}$, respectively. It may be noted that the ratio between these effective lifetime values is very approximately equal to the ratio between the respective equilibrium hole concentrations, $p_{o}$. 
TABLE III. EFFECT OF SURFACE RECOMBINATION ON THE EFFECTIVE LIFETIME OF HYPER-PURE COMPENSATED AND NON-COMPENSATED SILICON

\begin{tabular}{|l|l|l|l|l|l|l|l|}
\hline & $\begin{array}{l}\text { SRV } \\
(\mathrm{cm} / \mathrm{s})\end{array}$ & $\begin{array}{l}\tau_{\text {effective }}(\mu \mathrm{s}) \\
\left(\mathrm{cm}^{-3}\right)\end{array}$ & $\begin{array}{l}p_{o} \\
\left(\mathrm{~cm}_{\text {(front })}\right)\end{array}$ & $\begin{array}{l}V_{o c} \\
(\mathrm{mV})\end{array}$ & $\begin{array}{l}J_{s c} \\
(\mathrm{~mA} \\
\left.\mathrm{cm}^{2}\right)\end{array}$ & $\begin{array}{l}\eta \\
(\%)\end{array}$ \\
\hline Not comp & 270 & 34.8 & $4 \times 10^{16}$ & $4.1 \times 10^{14}$ & 670 & 34.55 & 19.4 \\
\hline Comp & 414 & 22.6 & $6.2 \times 10^{16}$ & $3 \times 10^{14}$ & 672 & 33.9 & 19.2 \\
\hline
\end{tabular}

That surface recombination should have a greater impact on the effective lifetime of compensated material can be understood by examining the definition of $\tau_{\text {eff }}$ given in Eq 3. In this wafer, $p \approx p_{0} \approx N_{A}-N_{D}$ and the photogeneration $G_{L}$ (one sun) is, in open-circuit, approximately equal to surface recombination (bulk recombination is negligible). The factor 2 in the following expression takes into account the two identical surfaces:

$$
G_{L}=\frac{\Delta n_{a v} W}{\tau_{e f f}}=2 J_{0} \frac{p n-n_{i}^{2}}{q n_{i}^{2}} \approx 2 J_{0} \frac{\Delta n\left(p_{0}+\Delta n\right)}{q n_{i}^{2}}
$$

As mentioned above, a higher $p_{o}$ is required in compensated $\mathrm{Si}$ due to its lower mobility. This means that a lower excess electron concentration $\Delta n$ is needed to reach a balance between generation and recombination. The lower $\Delta n$ then results in a

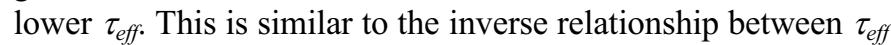
and dopant density that was experimentally observed in [19]. Just like the increased $\mathrm{V}_{\mathrm{oc}}$ in the previous section, the lower effective lifetime predicted for surface-dominated compensated $\mathrm{Si}$ wafers is a consequence of the particular dependence of the mobility on the total dopant density that we have assumed. A mobility model proportional to $\mathrm{N}_{\mathrm{A}}-\mathrm{N}_{\mathrm{D}}$ would result in no difference between compensated and non-compensated materials.

\section{CONCLUSIONS}

The theoretical study presented in this paper indicates that compensation doping may lead to some peculiarities in silicon solar cell performance. The higher total dopant density associated with compensation can be expected to lead to a lower mobility, both for majority and minority carriers. The latter would result in a shorter minority carrier diffusion length and a lower output current. The lower majority carrier mobility would, paradoxically, result in an increased output voltage, particularly in cases where the device is dominated by recombination in the bulk of the wafer, which is the most likely scenario for "dirty" silicon materials. This increase in $\mathrm{V}_{\text {oc }}$ (up to $10-20 \mathrm{mV}$ in some cases) helps to offset the reduction in $\mathrm{J}_{\mathrm{sc}}$. Nevertheless, it is possible that, in practice, compensation has a negative impact on bulk recombination, which would further reduce $\mathrm{J}_{\mathrm{sc}}$ and $\mathrm{V}_{\mathrm{oc}}$.

When characterizing compensated silicon, it is important to remember that surface recombination has a greater impact on a compensated wafer than on a non-compensated wafer of the same resistivity. Because of this, the measured effective lifetime will be lower in compensated than in uncompensated silicon, due to surface recombination. This again is a consequence of the higher free majority carrier density associated with compensation. It should be noted that these results are critically dependent on the assumed mobility models. Measurements of carrier mobility in compensated silicon are needed to clarify the matter.

\section{ACKNOWLEDGMENT}

A.C. is indebted to J. Bullon and J.M. Miguez of FerroAtlantica I+D, to D. Macdonald of ANU and B. Geerligs of ECN for useful information and helpful discussions on the topic of UMG and compensated silicon.

\section{REFERENCES}

[1] K. Peter, E. Enebakk, K. Friestad, R. Tronstad, C. Dethloff, Proc. 20th ECPVSEC, Barcelona 2005, p.615

[2] M. Kaes, G. Hahn, K. Peter, E. Enebakk, Proc. 4th WCPEC, Hawaii, 2006, p. 873.

[3] Photon, June 2008, p. 146

[4] R. Einhaus, J. Kraiem, F. Lissalde, S. Dubois, N. Enjalbert, R. Monna, Crystallisation of Purified Metallurgical Silicon, Proc. $33^{\text {rd }}$ IEEE Photovoltaic Specialists Conf., San Diego, May 2008, to be published.

[5] D. Macdonald, A. Cuevas and L. J. Geerligs Carrier lifetime studies of strongly compensated $p$-type Czochralski silicon, Proc. $23^{\text {rd }}$ European Photovoltaic Solar Energy Conf., Valencia, September 2008.

[6] A. Cuevas and R. Sinton, Simple modelling of solar cells, Proc. $23^{\text {rd }}$ European Photovoltaic Solar Energy Conf., Valencia, September 2008.

[7] Thurber, Mattis, Liu, and Filliben, J. Electrochem. Soc. 127, 1807 (1980), and J. Electrochem. Soc. 127, 2291 (1980).

[8] Arora, Hauser, and Roulston, IEEE Trans. on Electron Devices ED29(2), p. 292 (February 1982).

[9] D. A. Clugston and P. Basore, $26^{\text {th }}$ IEEE Photovoltaic Specialists Conf., Anaheim CA, pp. 207-210, 1997.

[10] S. Reggiani, M. Valdinoci, L. Colalongo, M. Rudan, G. Baccarani, A. D. Stricker, F. Illien, N. Felber, W. Fichtner and L. Zullino, IEEE Transactions on Electron Devices 49, 490 (2002).

[11] D. Macdonald, A. Cuevas and L. J. Geerligs, "Measuring dopant concentrations in compensated p-type crystalline silicon via ironacceptor pairing", Applied Physics Letters 92, 202119 (2008).

[12] F. Padovani, Effect of Compensation on the Segregation Coefficient as Deducted from Resistivity Measurements, J. Appl. Phys. 43, p.2003 (1972).

[13] J. Bullon, T. Margaria, A. Miranda and J.M. Miguez, Proc. Silicon for the Chemical and Solar Industries, IX, Oslo, June 23, 2008.

[14] E. Scheil, Z. Metallk. 34, 70 (1942)

[15] J. Bullon and J.M. Miguez, private communication.

[16] H. Dalaker and M. Tanstad, $22^{\text {nd }}$ European PVSEC, Milano, Sept 2007, pp. 1112-1116.

[17] J. Lilbal et al., 22 ${ }^{\text {nd }}$ European PVSEC, Milano, Sept 2007, pp. 11241129.

[18] S. Pizzini and C. Calligarich, J. Electrochem. Soc., vol. 131, pp 21282132 (1984)

[19] A. Cuevas, The effect of emitter recombination on the effective lifetime of silicon wafers, Solar Energy Materials and Solar Cells, vol. 57, pp. 277-290 (1999). 